\title{
Design of PCB Impedance Matching Inductors and Antennas for Single-Chip Communication Systems
}

\author{
J. Chung and S. Hamedi-Hagh \\ Electrical Engineering Department, San José State University, San José, CA 95192, USA \\ Correspondence should be addressed to S. Hamedi-Hagh, hamedi@email.sjsu.edu \\ Received 15 April 2008; Revised 25 July 2008; Accepted 25 November 2008 \\ Recommended by Chang-Ho Lee
}

\begin{abstract}
This paper presents the design of an inductor and an antenna for a portable device with GPS and FM capabilities. The inductor is designed to operate at the lower frequency FM band as part of a matching network and the antenna is designed to operate at the higher frequency GPS L1 band. The FR4 PCB used has a thickness of $1.6 \mathrm{~mm}$ with a dielectric constant of 3.8 and has two metallization layers. The inductor is designed with $1.5 \mathrm{~mm}$ trace width, 3.5 turns, and has a dimension of $14.5 \mathrm{~mm} \times 14.5 \mathrm{~mm}$. It has an inductance of $95 \mathrm{nH}$, a resistance of $2.9 \Omega$, a self-resonance frequency of $500 \mathrm{MHz}$, and a maximum Q of 51 from $100 \mathrm{MHz}$ to $200 \mathrm{MHz}$ (FM band). The antenna has a dimension of $49 \mathrm{~mm} \times 36 \mathrm{~mm}$ and is designed to operate at $1.5754 \mathrm{GHz} \mathrm{L} 1 \mathrm{band}$. It also has a return loss of $-36 \mathrm{~dB}$ and a measured bandwidth of $250 \mathrm{MHz}$.
\end{abstract}

Copyright () 2008 J. Chung and S. Hamedi-Hagh. This is an open access article distributed under the Creative Commons Attribution License, which permits unrestricted use, distribution, and reproduction in any medium, provided the original work is properly cited.

\section{Introduction}

Advances in portable handheld wireless devices create a demand for combining many features onto a single PCB. Our aim is to design RF PCB components for a portable device with both FM and GPS capabilities. Each wireless path in such a device consists of an antenna, a matching network, as well as the receiver IC, as shown in Figure 1.

The front-end antennas and the impedance matching inductors, shown in Figure 1, are optimized for the GPS L1 band at $1575.42 \mathrm{MHz}$ and the FM band at $100 \mathrm{MHz}$. The absence of transmitting signals in the handheld device and the large spectral and physical distances between the FM and GPS receiver front-ends keep their interactions and coupling at minimal.

To achieve the same impedance transformation ratio, the size of the impedance matching inductor in the FM band is larger than that in the GPS band due to the much lower operating frequency. The large size of the FM inductor increases its parasitic capacitors and decreases its self-resonance frequency. Maintaining high $Q$-factor below the already reduced self-resonant frequency in FM inductor requires more design challenges when compared with the GPS inductor and will be the focus of Section 2 in this paper.
The FM stations have limited area coverage compared with the GPS satellites which are located much farther. As a result, the received FM signals are much stronger due to the proximity of the transmitting stations and users. The low GPS signal power levels received at the user handhelds make design of the GPS antenna very challenging compared with the FM antenna and will be addressed in Section 3 of this paper.

Our paper is organized to correlate the design of the GPS antenna through characterization of the FR4 PCB obtained by the design of the FM impedance matching inductor. Section 2 presents the simulation and measurement results of the FM matching inductor that will lead to determination of the PCB traits. Section 3 discusses the design and measurement of the "L-ground h-type configuration with cornered patch" GPS antenna and, finally, Section 4 concludes the paper.

\section{FM Impedance Matching Inductor}

\subsection{Performance of the PCB Inductors}

Planar inductors can be created on either a silicon substrate or an FR4 PCB. Silicon integrated inductors have higher cost 


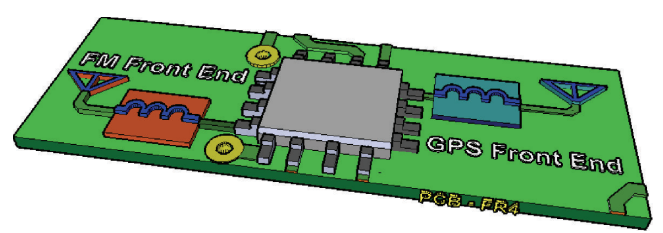

Figure 1: Block diagrams of the multiband portable device.

TABLE 1: PCB inductor versus silicon inductor.

\begin{tabular}{lccc}
\hline Tradeoffs for inductors built in: & Silicon & FR4 PCB & LTCC \\
\hline Area/Cost & High & Low & Med \\
Fabrication Complexity & High & Low & High \\
Frequency Ranges & High & Low & High \\
Inductance & Low & High & Med \\
Q-factor & Low & High & High \\
\hline
\end{tabular}

and lower Q-factor. Extra processing steps such as creating trenches in silicon [1] or using suspension methods [2] are required to increase the $Q$-factor of the silicon inductors which is typically lower than $25[1,2]$. Inductors designed in the standard PCB process with FR4 substrate inherently have the capability of having higher inductance and Q-factor. Low temperature cofired ceramic, LTCC, is another process that has higher cost and higher Q-factor compared with PCB. However, LTCC inductors need a ferrite core to yield large inductance which, in turn, reduces their self-resonance frequency $[3,4]$. A summary of comparison among silicon, FR4 PCB, and LTCC inductors is provided in Table 1.

The model of an inductor on FR4 PCB is shown in Figure 2 [5]. The PCB inductor has a resistance $R$, inductance $L$, and an interwinding capacitance $C$. Compared to the well-known silicon inductor model [6], the PCB inductor only represents a parasitic capacitance $\left(C_{\mathrm{FR} 4}\right)$. The $C_{\mathrm{FR} 4}$ is relatively large compared to the silicon parasitic, however, the inductance, $L$, in PCB is much larger than that in silicon which improves the $Q$-factor significantly.

The calculated $C_{\mathrm{FR} 4}$ for the inductor shown in Figure 3 is about $4 \mathrm{pF}$ with an interwinding capacitance of $95 \mathrm{fF}$. For a similar Q-factor of 50, LTCC inductors exhibit a smaller parasitic capacitance of $100 \mathrm{fF}$ [3] which improves their performance; however, the advantages of realizing PCB inductors are their lower cost and fabrication simplicity.

\subsection{Analysis and Design}

It is possible to determine the overall inductance of a planar structure by combining its distributed mutual and selfinductance components [7]. The inductance of a rectangular inductor, in nanohenries, can be approximately determined through

$$
L_{\text {square }} \cong 8.5 D N^{5 / 3},
$$

where $D$ is the distance between the two outer edges of the inductor, in centimeters, and $N$ is the number of turns within the inductor. For a $100 \mathrm{nH}$ inductance with 3 and $1 / 2, D$ is calculated to be $14.5 \mathrm{~mm}$ after grid adjustment. The

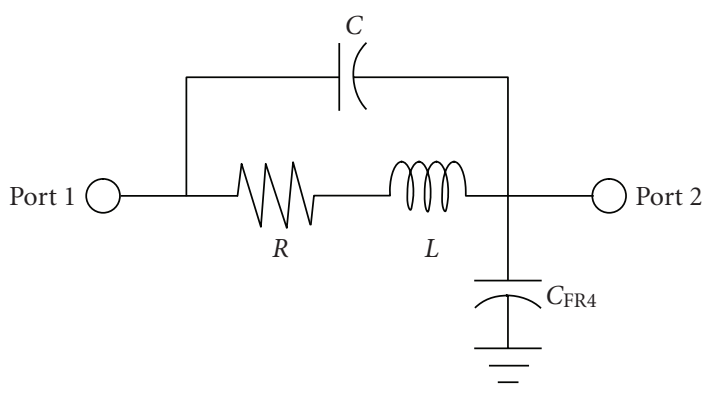

FIgure 2: Equivalent inductor model on FR4 PCB.

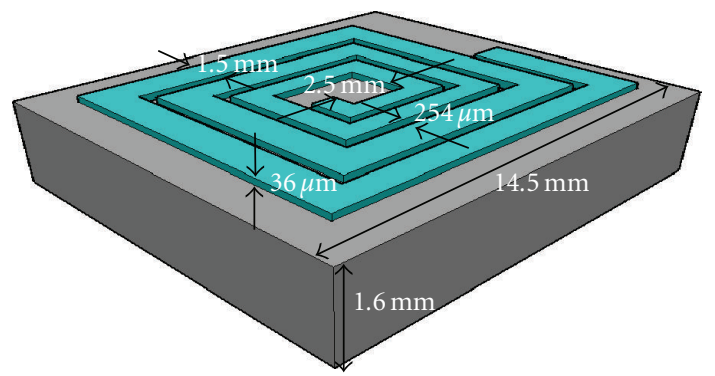

FIGURE 3: Dimensions of the proposed rectangular PCB inductor.

dimensions of the rectangular PCB inductor are shown in Figure 3. The width of the conductive trace is selected to be $1.5 \mathrm{~mm}$, the spacing between the two metal trances is selected to be $254 \mu \mathrm{m}$ and the distance between the two innercenter edges is selected to be $2.5 \mathrm{~mm}$ to attain a reasonable fit within the distance between the two outer edges.

The designed inductor is simulated using ADS and Sonnet CAD tools to obtain $S$-parameters which are converted to $Z$-parameters to extract the $L-R-Q$ parameters of the inductor. The goal of the parameter extractions is to cross check the results with calculations and measurement results that will be described in Section 2.3. This will aid us in better characterizing the FR4 PCB substrate before starting the antenna design.

The conductivity of the metal trace is determined to be $1.36 \times 10^{6} \mathrm{~S} / \mathrm{m}$, within the $100-200 \mathrm{MHz}$ operating frequency, through fitting simulation and measurement results that will be presented in Section 2.3. With the consideration of skin depth, the resistance of the inductor metal trace is $2.4 \Omega$ at the operating frequency. For the designed inductance of $100 \mathrm{nH}$, the determined $\mathrm{Q}$-factor is 52 .

\subsection{Calibration and Deembedding}

The implemented PCB inductor test structures are measured after calibrating the Agilent E8364B network analyzer using SOLT (short, open, load, thru). Essentially the calibration process adjusts the 12 internal error terms of the network analyzer by removing the effects of the cables [8]. The calibration process increases the accuracy of the measured $S$ parameters of the DUT, device under test [9].

The effects of the extra conductive traces, connecting the main PCB inductor to SMA connectors, are removed with 


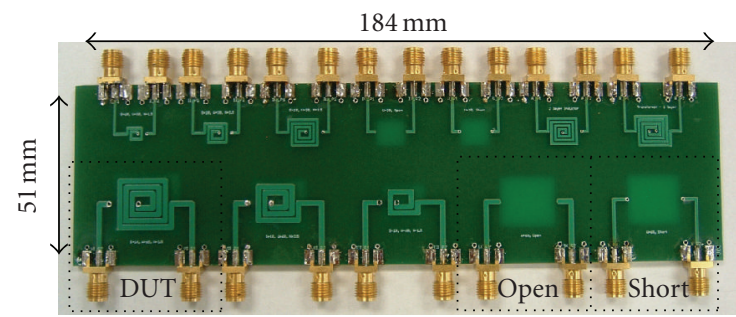

Figure 4: Implemented inductors with deembedding test structures.

deembedding using separate open and short structures [10]. The exclusion of the extra conductive traces and connectors is achieved by measuring the $S$-parameters of the DUT, the open and the short structures, followed by subtracting the corresponding admittance and impedance parameters, as expressed in [11]:

$$
\begin{aligned}
Y_{\mathrm{DUT} 1} & =Y_{\mathrm{DUT}}-Y_{\mathrm{OPEN}}, \\
Y_{\mathrm{SHORT} 1} & =Y_{\mathrm{SHORT}}-Y_{\mathrm{OPEN}}, \\
Z_{\mathrm{INDUCTOR}} & =Z_{\text {DUT1 } 1}-Z_{\text {SHORT1 }} .
\end{aligned}
$$

The implemented inductors and the deembedding test structures are shown in Figure 4. The inductor used for matching the FM chip to antenna is labeled "DUT" and is shown along with "open" and "short" test structures.

The impact of the deembedding can be clearly seen in Figure 5 where the original measured data for inductance, resistance, quality factor, and the self-resonant frequency is corrected using (2).

\subsection{Comparison of Simulation and Measurement Results}

The frequency-dependent inductance at port 1 , determined from the measured deembedded $Z$-parameters and the inductance equation in [12], is shown in Figure 6. This figure shows that the measured inductance peak occurs slightly sooner than simulated peaks, however, the overall measured inductance values are inline with the simulation profile. Both measurement and simulation results show only slight variance from the $100 \mathrm{nH}$.

The frequency-dependent resistance of the PCB inductor at port 1 , calculated from deembedded $Z$-parameters using resistance conversion equation in [12], is shown in Figure 7. This figure shows a spike of resistance due to the open circuit characteristic at resonant frequency. Although the measured and simulated results show a slight offset of the peak at the self-resonant frequency, the results agree very closely at the $100-200 \mathrm{MHz}$ operating frequency of interest.

Finally, the inductor $Q$-factor is obtained from the measured deembedded $Z$-parameters and using the conversion equation in [12]. The inductor quality factor is shown in Figure 8. The results show that the designed inductor has a maximum $Q$-factor of 50 at $100-200 \mathrm{MHz}$ operating frequency.

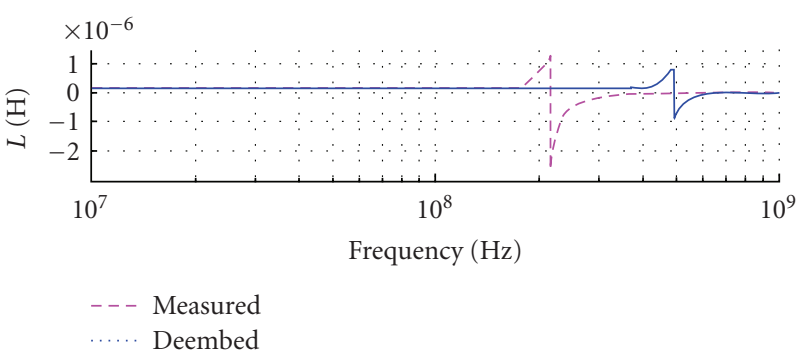

(a)

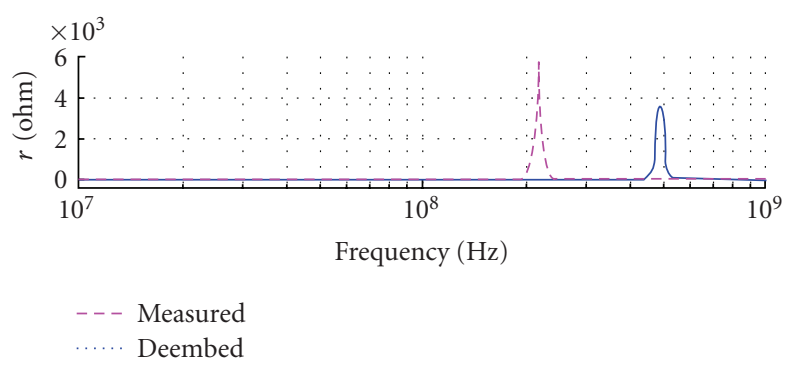

(b)

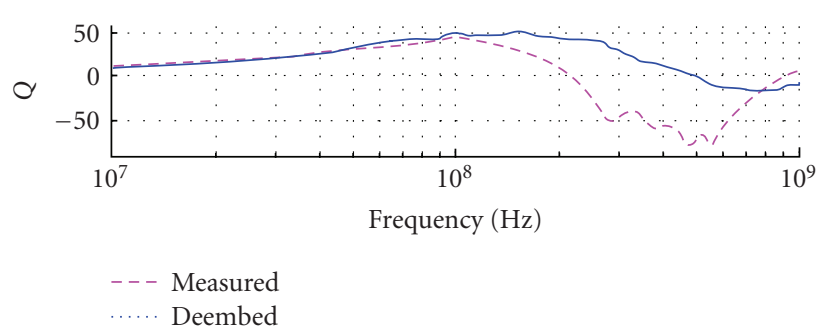

(c)

FIGURE 5: Effects of the trace deembedding on PCB inductor.

The measured profiles of Figures 6, 7, and 8 follow the simulation results, obtained from ADS and Sonnet CAD tools, fairly closely in terms of the magnitudes and the operating frequency for the inductance, the resistance, and the quality factor. These results are summarized in Table 2. From the table, Qmax obtained from ADS is closer to the measured value while Sonnet's $L-R$ parameters are closer to measured values.

\subsection{Inductor Extracted PCB Characteristics}

The inductor design process using calculations, simulations, and measurements allow characterization of the FM impedance matching inductor as well as the FR4 PCB. Accurate determination of the PCB substrate is very important before design of the crucial GPS antenna. The dielectric constant, $\varepsilon_{r}$, of the FR4 is experimentally refined to be of 3.8. The PCB substrate thickness of $1.6 \mathrm{~mm}$ and the conductor trace thickness of $36 \mu \mathrm{m}$ are both experimentally verified to be accurate. The original simulations were based on the theoretical conductivity of pure copper to be $5.8 \times 10^{7} \mathrm{~S} / \mathrm{m}$ [13]; however, the inductor design iteration determined that metal trace conductivity is $1.36 \times 10^{6} \mathrm{~S} / \mathrm{m}$. The simulators are accordingly optimized for the GPS antenna design. 


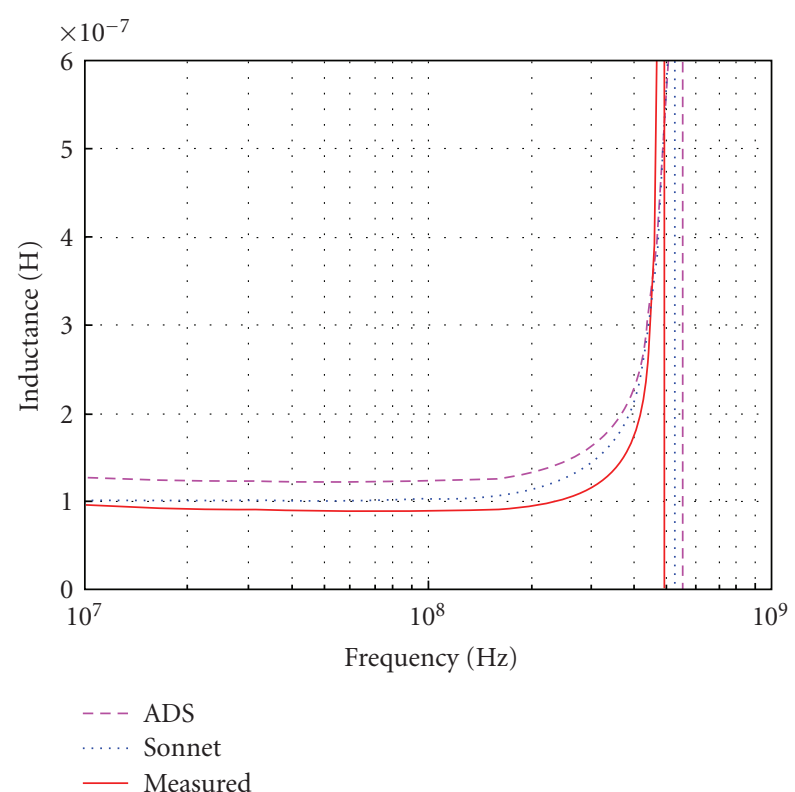

FIGURE 6: Simulated and measured inductance.

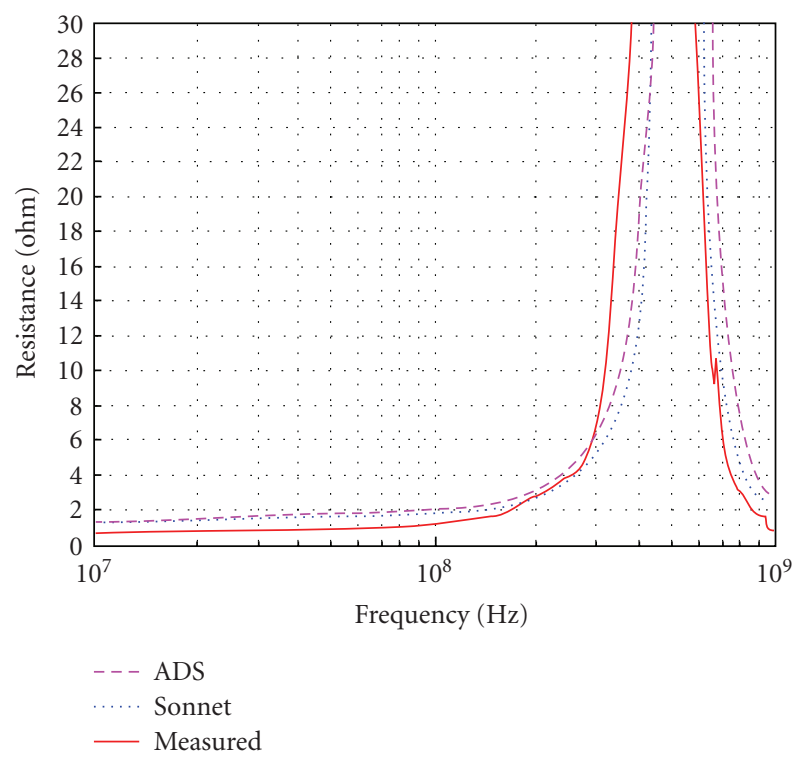

FIgURE 7: Simulated and measured resistance.

\section{GPS Antenna}

The GPS for civilian purposes is called the Standard Positioning Service, SPS [14]. SPS transmits messages on to the L1 signal at the carrier frequency of $1575.42 \mathrm{MHz}$ with a bandwidth of $2.046 \mathrm{MHz}$ and with right-hand circular polarization [14]. We propose an "L-ground h-type configuration with cornered patch" GPS antenna for the L1 civilian frequency.

\subsection{Performance of the PCB Antenna}

Patch antennas can be realized over FR4 PCB, silicon, and LTCC substrates. High performance silicon and LTCC

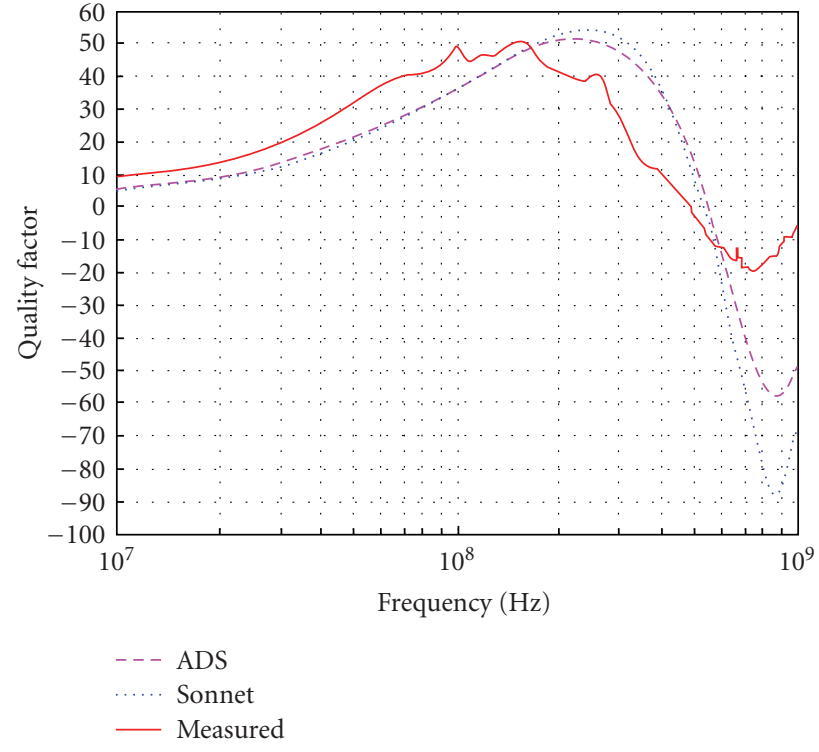

Figure 8: Simulated and measured Q-factor.

TABLE 2: The summary of the inductor characteristics.

\begin{tabular}{lcccc}
\hline & Calculated & ADS & Sonnet & Measured \\
\hline$L$ & $100 \mathrm{nH}$ & $129 \mathrm{nH}$ & $109 \mathrm{nH}$ & $95 \mathrm{nH}$ \\
$R$ & $2.4 \Omega$ & $3.3 \Omega$ & $2.7 \Omega$ & $2.8 \Omega$ \\
$Q \max$ & 52 & 52 & 55 & 51 \\
\hline
\end{tabular}

TABLE 3: PCB antenna versus silicon antenna.

\begin{tabular}{lccc}
\hline Tradeoffs for antennas built in: & Silicon & FR4 PCB & LTCC \\
\hline Area/Cost & High & Low & Med \\
Fabrication Complexity & High & Low & High \\
Frequency Ranges & High & Low & High \\
Radiation Efficiency & Low & High & Low \\
Dielectric Constant & High & Low & High \\
\hline
\end{tabular}

antennas are more costly and need more complex fabrication steps compared with the PCB antenna. The typical range of the PCB dielectric allows acceptable radiation $[15,16]$ while offering lower cost, as listed in Table 3.

The antenna design and analysis on FR4 PCB are presented in the next section.

\subsection{Analysis and Design}

The radiation patterns of an antenna can be studied based on a variety of models including the electric field characteristics. One particular method to determine the radiation pattern is based on the electric surface current model with rectangular patches [17]. In this antenna, the current characteristic, the ground planes, and the substrate contribute to the radiation patterns.

The starting point to design a reasonably compact antenna for the GPS applications can be the classic inverted-F structure $[18,19]$. After analyzing antenna parameters such 


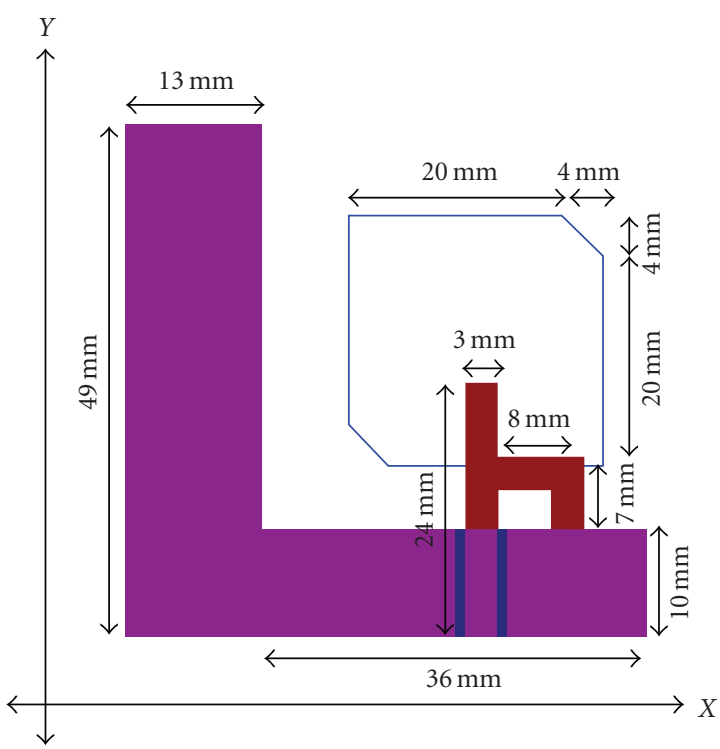

FIGURE 9: Geometry of the proposed inverted-F antenna.

as polarization and radiation patterns, we propose the " $\mathrm{L}$ ground h-type configuration with cornered patch" antenna, as shown in Figure 9.

The left vertical side of the "L" shaped ground plane along the $Y$ axis in Figure 9 acts as a unique reflector to create a strong front beam in the $+X$ direction. The proposed reflector influences the antenna directivity at $\varphi=0^{\circ}$ by reflecting the opposite fields at $180^{\circ}$ direction, creating an intense forward power and focused gain. Our goal is also to create a beam in the radiation direction of $\theta=70^{\circ}, 20^{\circ}$ above the $x-y$ plane, so that the additional tilt from the use of the FM-GPS portable device would point to the sky.

In order to provide a patch antenna design with circular polarization, the two opposite corners of a square patch under the antenna are removed [19-21]. Removing the two diagonal opposing corners of the square patch creates a $90^{\circ}$ phase shift in the excited wave mode creating less capacitance compared to the standard square edges [21]. The patch creates right-hand circular polarization [13], where the signal alignment is on the $Z-Y$ axes and the propagation is in the $+X$ direction.

Similar to the inverted-F antenna [20, 21], the h-shape portion of our designed antenna provides an adjustment for the input impedance. The h-shape portion, just as the classic inverted-F, is sensitive to the center frequency so that any process variation affecting the trace dimensions will create a drift in the center of the operating frequency. Therefore, although the GPS specifications require only a bandwidth of $2.046 \mathrm{MHz}$, our designed bandwidth is greatly increased as a safeguard to ensure full antenna functionality after including $20 \%$ process variation. The first antenna iteration is designed with a wide bandwidth of $300 \mathrm{MHz}$ to ensure that the ideal center frequency of $1.5754 \mathrm{GHz}$ is covered even in the worst process variation case. The bandwidth is determined relative to the frequency and the geometry through the altered

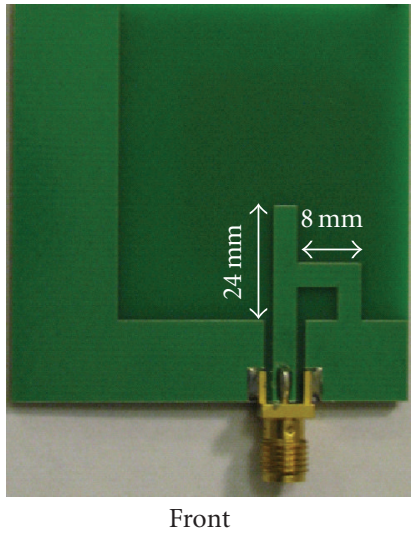

(a)

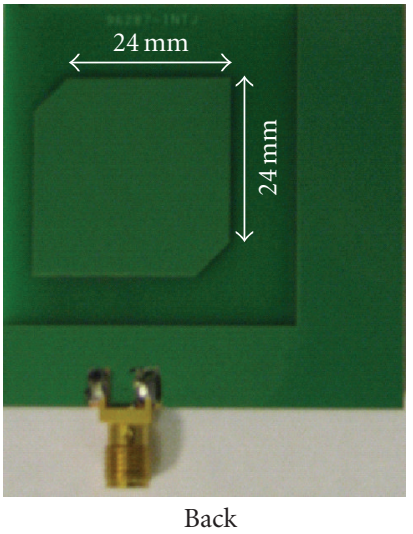

(b)
Figure 10: Front and back pictures of the designed antenna.

square patch portion of the antenna in Figure 9, which can be determined through [20]

$$
\mathrm{BW} \cong 50 h f^{2},
$$

where $h$ is the height of the patch in centimeters, $f$ is the frequency in gigahertz, and BW is the bandwidth in megahertz. After reiterating the bandwidth calculation from grid adjustment, the patch height is selected to be $24 \mathrm{~mm}$ and the final calculated bandwidth is $297 \mathrm{MHz}$ using $1.5754 \mathrm{GHz}$ as the center frequency.

\subsection{Simulations and Measurement Results}

The implemented "L-ground h-type configuration with cornered patch antenna" is shown in Figure 10.

The simulated and measured radiation patterns of the designed antenna are shown in Figure 11(a) for the $x y$-plane and Figure 11(b) for the $y z$-plane. As expected, the main beam in the $x y$-plane, shown in Figure 11(a), is at $\varphi=0^{\circ}$ with high intensity between $30^{\circ}$ and $330^{\circ}$ created by the reflectors in the $x y$-plane. Also, the simulated and measured area of interest at $\varphi=0^{\circ}$ is in close agreement. In relation to the functionality of the FM/GPS handheld device, the measured angle of radiation for the antenna in the $y z$-plane from Figure 11(b) shows a relatively higher intensity around $15^{\circ}-45^{\circ}$ above the $x y$-plane to assist the user, holding the handheld device, in pointing the maximum antenna beam toward the sky direction.

The directivity and gain for the maximum radiation intensity, obtained from both ADS and Sonnet CAD tools, is at $\varphi=0^{\circ}$ and $\theta=72^{\circ}$ which correlates to the radiation pattern because the $72^{\circ}$ difference from the $Z$-axis results in the tilt angle of $18^{\circ}$. At the mentioned angle where the maximum radiation intensity occurs, the directivity is $5.0 \mathrm{dBi}$ and the gain is $5.01 \mathrm{dBi}$.

Another important antenna parameter is the axial ratio, shown in Figure 12, where $0 \mathrm{~dB}$ indicates ideal circular polarization. Figure 12 shows that at $1.5754 \mathrm{GHz}$, the axial ratio is close to $1.2 \mathrm{~dB}$ in the direction of maximum radiation. 


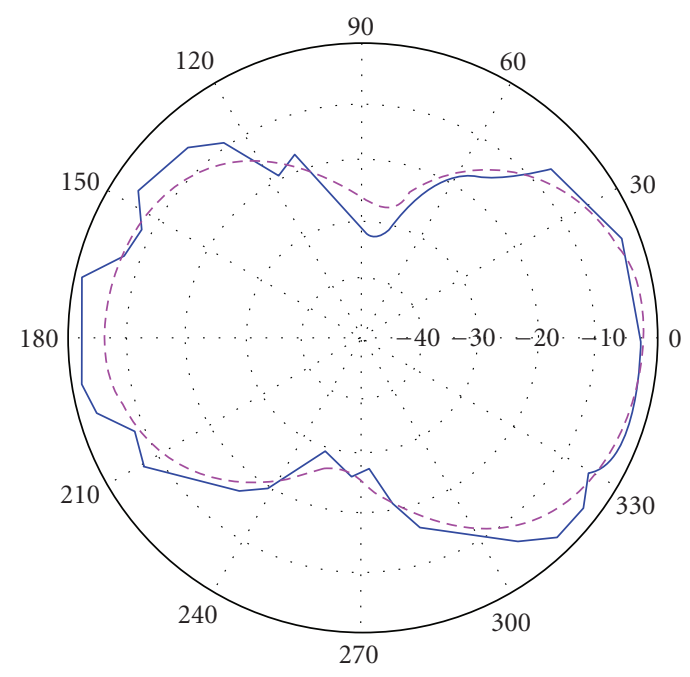

- - - Simulated

- Measured

(a)

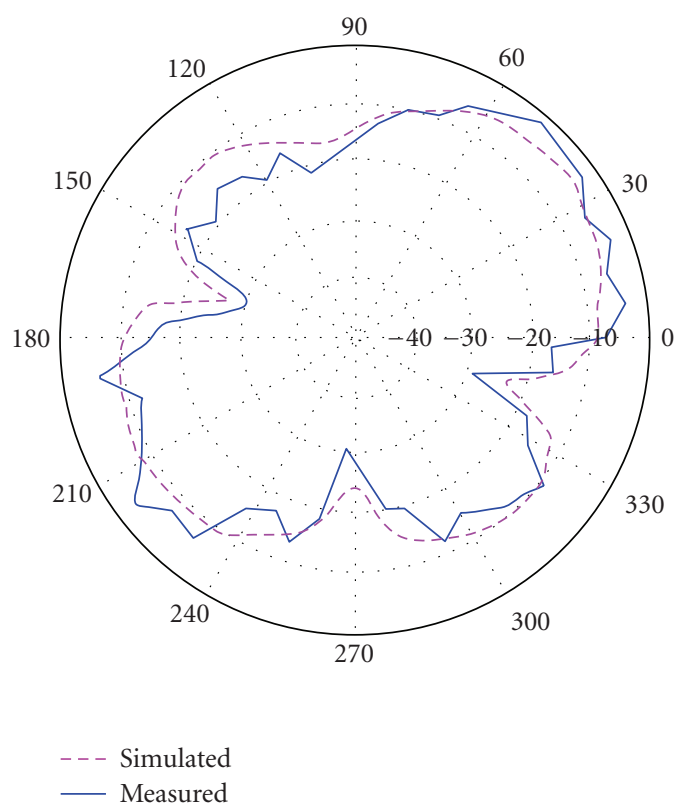

(b)

Figure 11: Radiation pattern (a) $x y$-plane, (b) $y z$-plane.

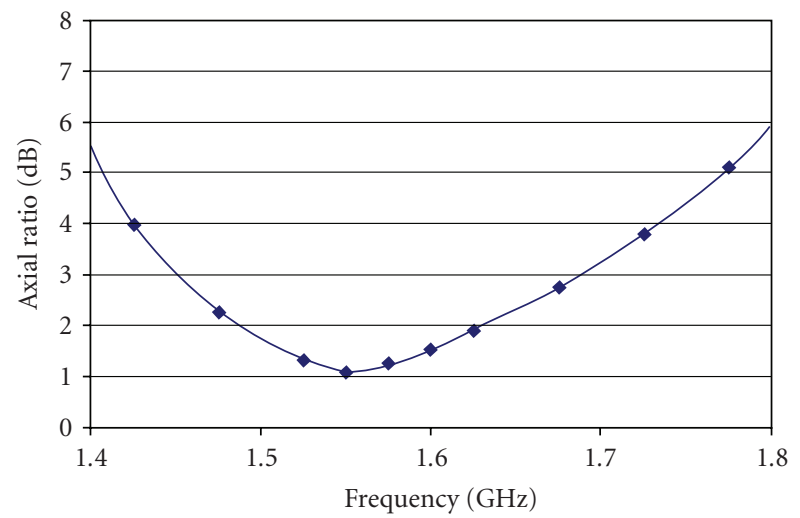

Figure 12: Axial ratio.

The maximum power is transferred from the antenna to the receiver IC when their impedance is matched. The simulated and measured $S_{11}$ parameters of the antenna are shown in Figure 13 and listed in Table 4. The measured results show that the antenna $S_{11}$ at $1.5754 \mathrm{GHz}$ is $-36 \mathrm{~dB}$, which is sufficient for GPS applications. Compared to the measurement, the ADS simulator presents accurate results in terms of center frequency and the Sonnet simulator presents accurate results in terms of bandwidth profile due to different modeling of metal traces.

\section{Conclusion}

The design and measurements of antenna and inductor components of a GPS/FM receiver system were presented in this paper. The FM matching inductor was designed to correlate to the GPS antenna through the PCB characteristics, covering

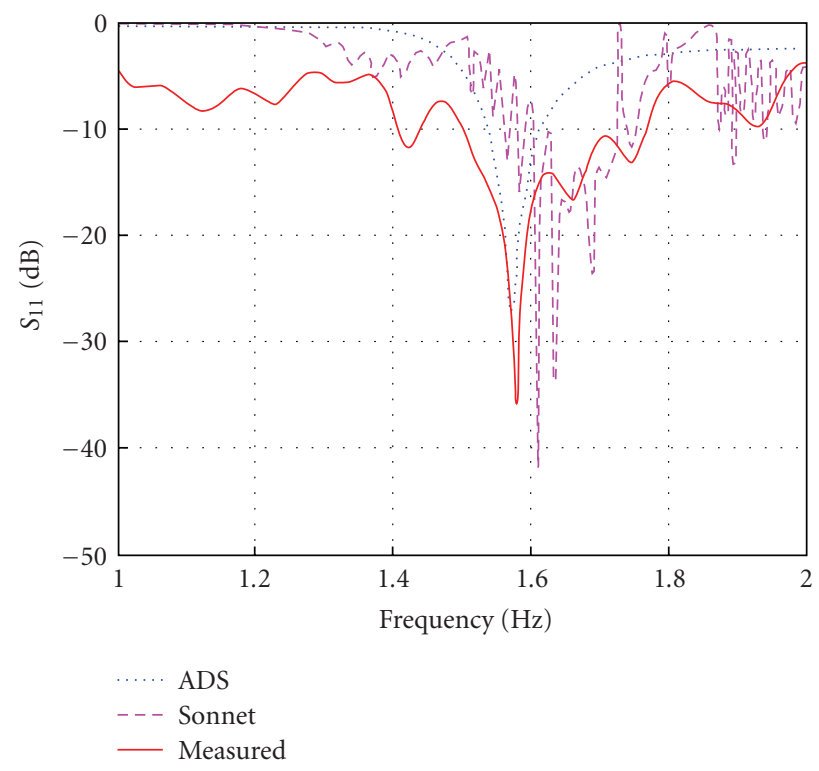

Figure 13: $S_{11}$ parameters of the simulated and measured GPS antenna.

TABLE 4: GPS antenna frequency and bandwidth.

\begin{tabular}{lcccc}
\hline & Goal & ADS & Sonnet & Measured \\
\hline$\Delta$ from center & 0 & $4 \mathrm{MHz}$ & $25 \mathrm{MHz}$ & $6 \mathrm{MHz}$ \\
BW & $297 \mathrm{MHz}$ & $75 \mathrm{MHz}$ & $210 \mathrm{MHz}$ & $250 \mathrm{MHz}$ \\
\hline
\end{tabular}

both frequencies. The measured results of the FM matching inductor allowed feedback to optimize the simulator in order to design the proposed GPS antenna. 
The inductor was designed with $1.5 \mathrm{~mm}$ trace width, 3.5 turns, and a dimension of $14.5 \mathrm{~mm} \times 14.5 \mathrm{~mm}$. It yielded an inductance of $95 \mathrm{nH}$, a resistance of $2.9 \Omega$, a selfresonance frequency of $500 \mathrm{MHz}$, and a maximum $Q$ of 51 from $100 \mathrm{MHz}$ to $200 \mathrm{MHz}$ (FM band). The antenna has a dimension of $49 \mathrm{~mm} \times 36 \mathrm{~mm}$ and was designed to operate at $1.5754 \mathrm{GHz} \mathrm{L} 1$ band. It yielded a return loss of $-36 \mathrm{~dB}$ and a measured bandwidth of $250 \mathrm{MHz}$.

\section{Acknowledgments}

This work was measured at RFICS laboratory at San José State University. The authors would also like to thank Sonnet Software Inc. and Agilent ADS for providing the use of their tools.

\section{References}

[1] S. Sridharan, W. Grande, and P. R. Mukund, "High Q embedded inductors in silicon for RF applications," in Proceedings of the 15th Annual IEEE International ASIC/SOC Conference, pp. 346-349, Rochester, NY, USA, September 2002.

[2] H. Ronkainen, H. Kattelus, E. Tarvainen, T. Riihisaari, M. Andersson, and P. Kuivalainen, "IC compatible planar inductors on silicon," IEE Proceedings: Circuits, Devices and Systems, vol. 144, no. 1, pp. 29-35, 1997.

[3] K. C. Eun, Y. C. Lee, J. W. Lee, M. S. Song, and C. S. Park, "Fully embedded LTCC spiral inductors incorporating air cavity for high Q-factor and SRF," in Proceedings of the 54th Electronic Components and Technology Conference (ECTC'04), vol. 1, pp. 1101-1103, Las Vegas, Nev, USA, June 2004.

[4] T. B. Chan, H.-C. Lu, J.-K. Zeng, and C. C.-P. Chen, "LTCC spiral inductor modeling, synthesis, and optimization," in Proceedings of the Conference on Asia and South Pacific Design Automation (ASP-DAC'08), pp. 768-771, Seoul, Korea, March 2008.

[5] S. Stalf, "Printed inductors in RF consumer applications," IEEE Transactions on Consumer Electronics, vol. 47, no. 3, pp. 426-435, 2001.

[6] J. R. Long and M. A. Copeland, "The modeling, characterization, and design of monolithic inductors for silicon RF IC's," IEEE Journal of Solid-State Circuits, vol. 32, no. 3, pp. 357-369, 1997.

[7] W. B. Kuhn, A. Elshabini-Riad, and F. W. Stephenson, "Centretapped spiral inductors for monolithic bandpass filters," Electronics Letters, vol. 31, no. 8, pp. 625-626, 1995.

[8] D. C. DeGroot, K. L. Reed, and J. A. Jargon, "Equivalent circuit models for coaxial OSLT standards," in Proceedings of the 54th ARFTG Conference Digest, pp. 103-115, Atlanta, Ga, USA, December 1999.

[9] D. Rytting, "Network analyzer error models and calibration methods," Hewlett-Packard Company, White Paper, September 1998, http://cpd.ogi.edu/IEEE-MTT-ED/Network Analyzer error Models and Calibration Methods.pdf.

[10] M. D. DuFault and A. K. Sharma, "A novel calibration verification procedure for millimeter-wave measurements," in Proceedings of the IEEE MTT-S International Microwave Symposium Digest, vol. 3, pp. 1391-1394, San Franscisco, Calif, USA, June 1996.

[11] D. M. Jamal and T. A. Fieldly, CMOS RF Modeling, Characterization and Applications, World Scientific, Singapore, 2002.
[12] M. Drakaki, A. A. Hatzopoulos, and S. Siskos, "CMOS inductor performance estimation using Z- and S-parameters," in Proceedings of the IEEE International Symposium on Circuits and Systems (ISCAS '07), pp. 2256-2259, New Orleans, La, USA, May 2007.

[13] D. M. Pozar, Microwave Engineering, 3rd, John Wiley \& Sons, Hoboken, NJ, USA, 2005.

[14] "Global positioning system standard positioning service standard," October 2001, http://pnt.gov/public/docs/SPS-2001final.pdf.

[15] I. K. Kim, N. Kidera, S. Pinel, et al., "Linear tapered cavitybacked slot antenna for millimeter-wave LTCC modules," IEEE Antennas and Wireless Propagation Letters, vol. 5, no. 1, pp. 175-178, 2006.

[16] P. V. Bijumon, A. P. Freundorfer, M. Sayer, and Y. M. M. Antar, "On-chip silicon integrated cylindrical dielectric resonator antenna for millimeter wave applications," in Proceedings of the International Symposium on Signals, Systems and Electronics (ISSSE '07), pp. 489-492, Montreal, Canada, July-August 2007.

[17] R. Garg, P. Bhartia, I. Bahl, and A. Ittipiboon, Microstrip Antenna Design Handbook, Artech House, Norwood, 2001.

[18] Q. Zhu, K. Fu, and T. Liang, "Analysis of planar inverted Fantenna using equivalent models," in Proceedings of the IEEE Antennas and Propagation Society International Symposium, vol. 3A, pp. 142-145, Washington, DC, USA, July 2005.

[19] G. Qasim, Z. Wei, and Z. Jianguo, "Inverted F-antenna for mobile communication," in Proceedings of the Asia-Pacific Microwave Conference (APMC'05), vol. 5, p. 4, Suzhou, China, December 2005.

[20] G. Kumar and K. P. Ray, "An introduction to microstrip antennas," in Broadband Microstrip Antennas, chapter 1, pp. 11-18, Artech House, Norwood, NJ, USA, 2003.

[21] R. Bancroft, "Rectangular microstrip antennas," in Microstrip and Printed Antenna Design, chapter 2, pp. 37-48, Noble, Atlanta, Ga, USA, 2004. 

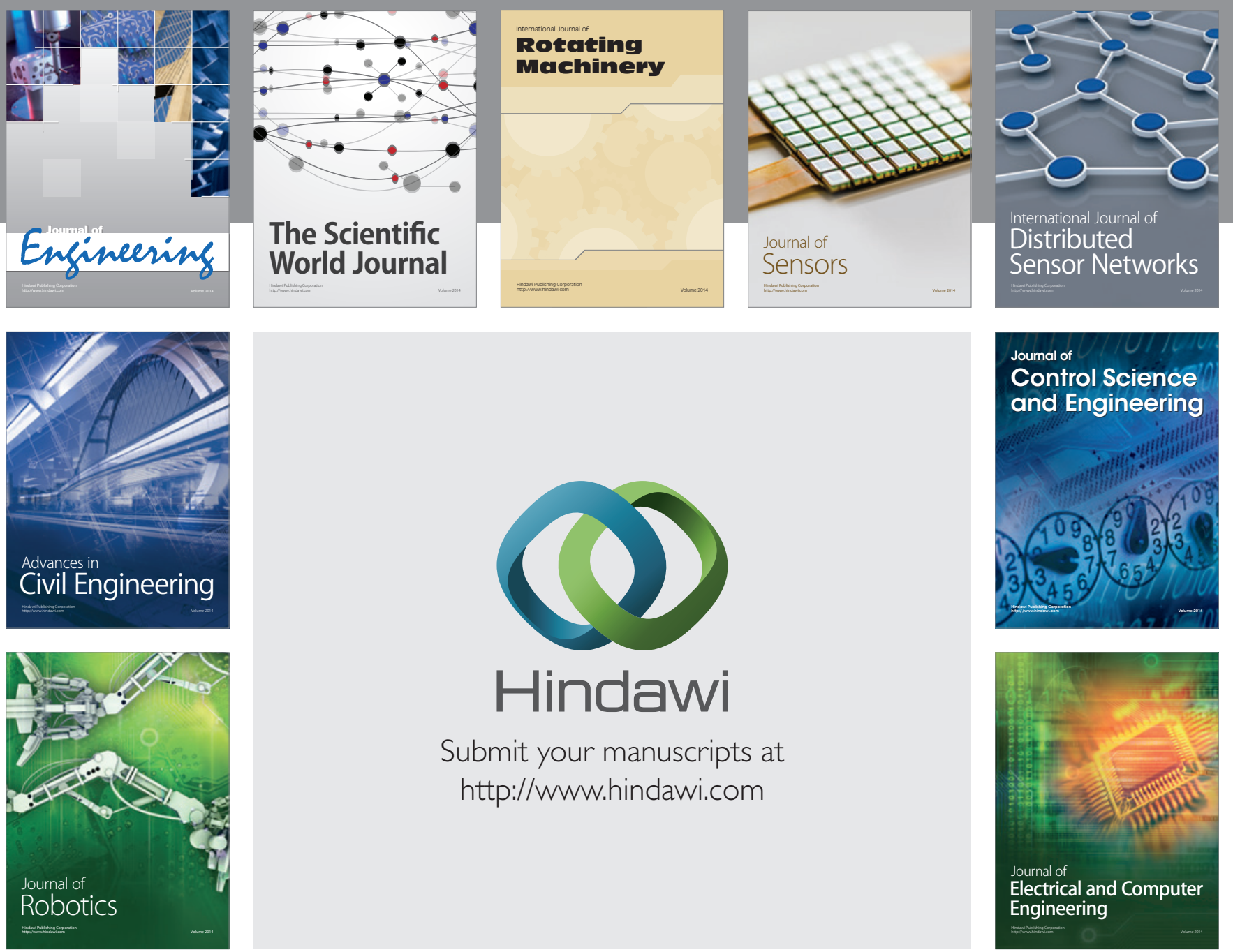

Submit your manuscripts at

http://www.hindawi.com
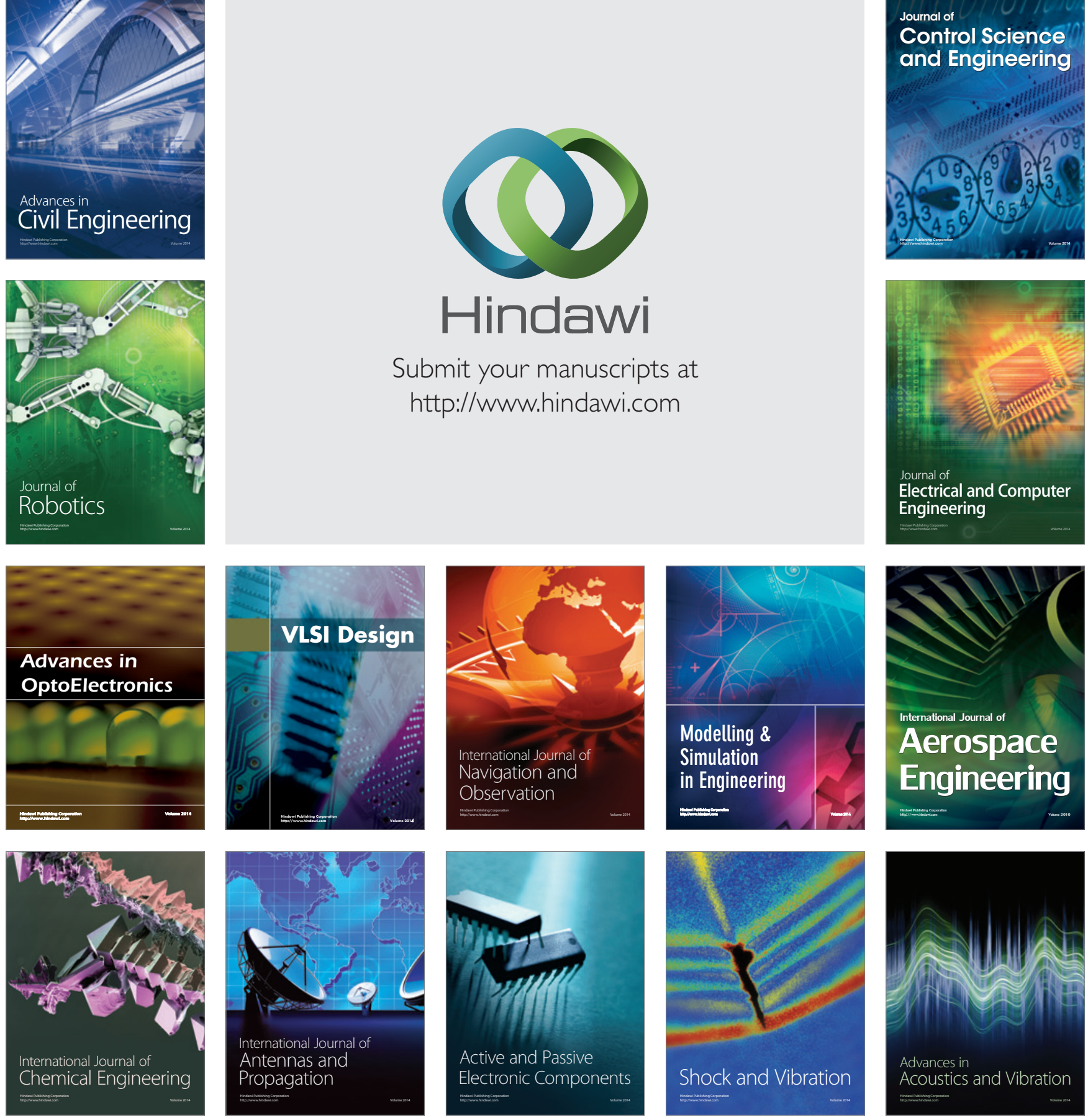